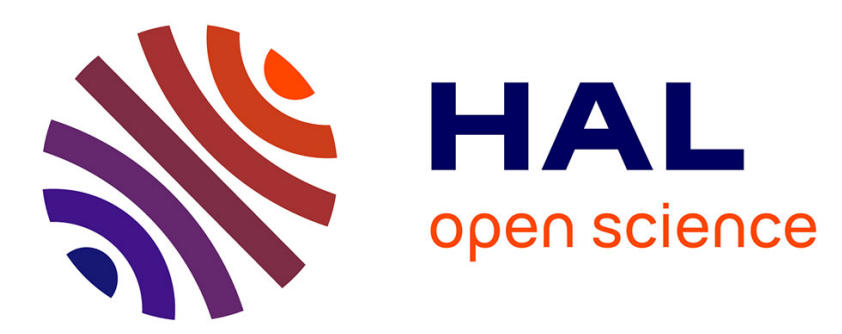

\title{
Hormonal responses in gambling versus alcohol abuse: a review of human studies
}

\author{
Yansong Li, Nicolas Ramoz, Edmund Derrington, Jean-Claude Dreher
}

\section{To cite this version:}

Yansong Li, Nicolas Ramoz, Edmund Derrington, Jean-Claude Dreher. Hormonal responses in gambling versus alcohol abuse: a review of human studies. Progress in Neuro-Psychopharmacology and Biological Psychiatry, 2020, 100, 10.1016/j.pnpbp.2020.109880 . hal-02353112

\section{HAL Id: hal-02353112 \\ https://hal.science/hal-02353112}

Submitted on 17 Nov 2020

HAL is a multi-disciplinary open access archive for the deposit and dissemination of scientific research documents, whether they are published or not. The documents may come from teaching and research institutions in France or abroad, or from public or private research centers.
L'archive ouverte pluridisciplinaire HAL, est destinée au dépôt et à la diffusion de documents scientifiques de niveau recherche, publiés ou non, émanant des établissements d'enseignement et de recherche français ou étrangers, des laboratoires publics ou privés. 


\title{
Hormonal responses in gambling versus alcohol abuse: A review of human studies
}

\author{
3 Yansong $\mathrm{Li}^{\mathrm{a}, \mathrm{b}, *}$, Nicolas Ramoz $^{\mathrm{c}, * *}$, Edmund Derrington ${ }^{\mathrm{d}}$, Jean-Claude Dreher ${ }^{\mathrm{d}, * * *}$ \\ a Competition, Addiction and Social Neuroscience LAB, Department of Psychology, School of Social AND Behavioral Sciences, \\ NANJING University, NANJing, CHINA \\ ${ }^{b}$ Institute for BRaIN Sciences, NANJING University, NANJING, CHINA \\ c VULNERABILITY of PSYCHIATRIC AND Addictive Disorders, Institute of PSYCHIATRY AND Neuroscience of PARIS, INSERM UMRS1266, \\ PARIS, FRANCE \\ d Neuroeconomics Laboratory, Institut des Sciences Cognitives Marc Jeannerod, CNRS UMR 5229, Bron, France
}

\begin{abstract}
The endocrine system plays an essential role in communication between various organs of the body to maintain homeostasis. Both substance use disorders (SUDs) and non-substance abuse disrupt this system and lead to hormonal dysregulations. Here, we focus on the comparison between the function of the endocrine system in gambling disorders and alcohol addiction to understand the commonalities and differences in their neurobiological and psychological underpinnings. We review human research to compare findings on gambling addiction and alcohol dependence pertaining to the dynamic interplay between testosterone and cortisol. Understanding and classifying similarities in hormonal responses between behavioural addiction and SUDs may facilitate development of treatments and therapeutic interventions across different types of addictive disorders, while describing differences may shed light on therapeutic interventions for specific disorders. Although research on gambling addiction is in its infancy, such evaluation may still have a positive effect for addiction research, thereby stimulating discovery of "crossover" pharmacotherapies with benefits for both SUDs and nonsubstance addictions.
\end{abstract}

\section{Introduction}

Addiction is usually defined as a psychological and physical inability to stop consuming a substance or activity, even though it is causing harmful effects to a person's health and on their social relationships (Goodman, 1990, 2008; Sussman and Sussman, 2011; West and Brown, 2013). Some addictions involve dependence on chemical substances, and for this reason are called substance abuse disorders (SUDs) (Heather, 1998). On the other hand, building on Peele's notion (Peele and Brodsky, 1975), addiction does not necessarily have to depend on substance abuse. Instead, it may also refer to a range of excessive behaviours which involve an inability to stop partaking in activities such as gambling (Griffiths, 1990; Rogers, 1998), video game playing (Keepers, 1990), media use (Horvath, 2004) and porn consumption (Phillips et al., 2015). An individual has a behavioural addiction in these circumstances (Association, A.P, 2013). Because of growing evidence from behavioural, neuroimaging and genetic studies over the past decade in the field of behavioural addiction, a recent area of debate is emerging (Alavi et al., 2012; Frascella et al., 2010; Leeman and Potenza, 2012; Wareham and Potenza, 2010). What are the similarities and differences between these two major categories of addictive disorders? Identifying the common and unique features they have may not only have important theoretical implications for understanding neuropsychological mechanisms underlying both, but also have practical implications for improving categorization, assessment, and treatment strategies (Grant et al., 2006). To date, a number of research articles (including systematic reviews and meta-analyses) have attempted to address this issue. Multiple similarities and differences between behavioural addiction and SUDs have been found at the psychological and neurobiological levels, including features of impulsivity and compulsivity (Choi et al., 2014; Lawrence et al., 2009a, 2009b; Leeman and 
Potenza, 2012), a core brain network of dysfunctional brain regions including ventromedial prefrontal cortex and striatum (Contreras- Rodríguez et al., 2016; Lawrence et al., 2009b; Leeman and Potenza, 2012; Potenza, 2008; Verdejo-Garcia et al., 2015; Worhunsky et al., 2017), and neurotransmitter systems such as the dopaminergic and serotonergic systems (Blum et al., 2000; Leeman and Potenza, 2012; Potenza, 2008). Recent meta-analyses of $\mathrm{fMRI}$ data have also identified distinct disruptions of reward-processing at the time of reward outcome (Luijten et al., 2017). More specifically, individuals with SUDs showed increased activity in the ventral striatum, whereas those with gambling disorders showed decreased activity in the dorsal striatum, compared with healthy controls.

In addition to the association of addiction with large scale brain networks and neurotransmitter systems, addictions have the tendency to cause changes to the endocrine system that produces hormones, chemical signals disseminated through the whole body (Kiefer and Wiedemann Kiefer and Wiedemann, 2004). Over the past decades, considerable efforts have been directed to exploring the potential relationship between substance use/dependence and the endocrine system. To date, the majority of evidence suggests an interplay between substance use/dependence and many hormone systems, including steroid hormones (Lynch and Sofuoglu, 2010). Furthermore, a number of recent systematic reviews and meta-analyses attempted to describe more precisely how steroid hormones interact with substance use and in turn contribute to the development of substance dependence (Bawor et al., 2015; Erol et al., 2019; Hudson and Stamp, 2011; Lee et al., 2002). On the other hand, despite that research on nonsubstance addictions is in its infancy, empirical evidence in support of the relationship between nonsubstance abuse (gambling disorders) and the endocrine system has gradually accumulated over the past decade. Building on these considerations, we believe that it may be of benefit to summarize the findings and identify commonalities and differences between these two categories of addictive disorders in terms of their association with the endocrine system.

To address this issue, here, we present a - review of the human studies that investigated the association of steroid hormones with these two addictive disorders. Although there is evidence showing interactions between substance abuse and many hormone systems (Rachdaoui and Sarkar, 2017), comparable findings are few with regard to behavioural addiction. Accordingly, we focused on two major classes of steroid hormones: stress hormones (cortisol) and sex hormones (testosterone). Using alcoholism as an example of SUDs and gambling disorders as a common example of a behavioural addiction, we review specific hormonal explanations that may contribute to the variable behavioural effects of alcohol and gambling (see comparison between alcohol and nutrients in Alhadeff et al., 2019). Specifically, first, we will briefly review of the structure and functions of the hypothalamic-pituitary-gonadal (HPG) and hypothalamicr-pituitary-adrenal (HPA) axes. Then, we will discuss results pertaining to the interactions between substance or nonsubstance abuse and testosterone or cortisol, with an emphasis on commonalities and differences between gambling disorders and alcohol dependence. Finally, we conclude with suggestions for future studies. Where applicable, observations from healthy samples are discussed first, followed by findings in clinical addictive samples.

\section{The HPG and HPA axes: a brief review}

The HPG axis, which is highly conserved throughout evolution, plays an important role in regulating reproductive function, life cycle and also in coordinating sexual dimorphism and behaviour. Gonadotropinreleasing hormone $(\mathrm{GnRH})$, is produced and secreted by the hypothalamus. GnRH stimulates the anterior pituitary to secrete follicle-stimulating hormone (FSH) and leuteinizing hormone (LH) from gonadotropic cells into the general circulation (Fig. 1A). FSH and $\mathrm{LH}$ are gonadotropins that regulate the development of follicles (i.e., folliculogenesis) in females and of sperm in males. In females, under the presence of these gonadotropins, the ovaries produce and secrete the hormone estradiol. The increased level of estradiol regulates the surge in LH levels through a feedback mechanism that usually occurs during midcycle of the menstrual cycle, which then activates ovulation and the development of the corpus luteum. This in turn produces and secretes the hormone progesterone that helps maintain pregnancy. In males, LH increases the production and secretion of testosterone by Leydig cells in the testis, whereas FSH controls spermatogenesis. 
Feedback loop mechanisms regulate the HPG axis activity. Thus, testosterone regulates its own production and secretion by acting on the hypothalamus and anterior pituitary. This leads to the inhibition of the secretion of $\mathrm{GnRH}$, LH and FSH. In fact, negativeand positive-feedback actions are observed for both estradiol and progesterone that stimulate or inhibit the release of GnRH, LH, and FSH (Sarkar, 1983) (Fig. 1A). The central nervous system acts both as a source and target of these gonadal steroid hormones because they pass through the blood brain barrier to be secreted in the peripheral blood. The influences of gonadal steroid hormones is observed in the brain through widespread modulation of both the recent neocortical regions and evolutionarily ancient brain areas of limbic nuclei, such as the basal ganglia and amygdala.

In contrast, the HPA axis is the endocrine system that coordinates the body's physiologic response to stress and regulates many of the body's physiological processes (e.g., metabolic, cardiovascular, and immune functions) to allow the body to maintain homeostasis (Dallman et al., 1994; Sapolsky, 2003; Selye, 1936). This hormonal system includes several major nodes: the hypothalamus, the anterior pituitary gland and the adrenal cortex (Fig. 1B). Neurons in the paraventricular nucleus (PVN) of the hypothalamus secret the corticotropin-releasing hormone $(\mathrm{CRH})$, also called corticotropin-releasing factor (CRF), into the anterior pituitary via the hypophysial portal circulation. At the anterior pituitary, CRH stimulates the production and secretion of adrenocorticotropic hormone (ACTH), which is released into the systemic circulation where it binds to melanocortin type 2 receptors on cells in the outer layer of the adrenal glands (the adrenal cortex) that are located on top of the kidneys. In the adrenal cortex, ACTH stimulates release of glucocorticoid hormones-mainly cortisol in humans (Fig. 1B). The normal functioning of the HPA axis depends on intricate regulation through glucocorticoid receptors found in the anterior pituitary, hypothalamus, amygdala and hippocampus. The HPA is controlled through several feedback mechanisms (Plotsky, 1991), the principal one involving the release of cortisol through a negativefeedback action that inhibits CRH secretion (Fig. 1B). Testosterone in alcohol use/dependence and gambling/ gambling disorders

\subsection{Testosterone AND ALCOHOL use/dependence}

There is growing evidence that a relationship between testosterone levels and alcohol consumption is found in adults. A number of prior studies have found that high testosterone levels correlated positively with alcohol consumption in healthy individuals (e.g. college students, with a larger effect in males) (La Grange et al., 1995) and in healthy older males (Wu et al., 1995). This association has also been reported in individuals with type II alcoholism with moderate dependence, characterized by early onset, disruptive behavior and criminality (Stålenheim et al., 1998). These results suggest that males with high testosterone levels tend to show increased risk for alcohol use than males with low testosterone levels. Accordingly, in alcohol-dependent populations, an increase in testosterone concentrations should co-occur with abstaining from alcohol (Hasselblatt et al., 2003; Heinz et al., 1995; King et al., 1995; Lenz et al., 2017) or alcohol withdrawal (Walter et al., 2006a) compared to healthy controls. Such an association of increased testosterone levels and an elevated risk for alcohol consumption in men may be partly accounted for by the extent of prenatal testosterone exposure. A study found that men born with congenital adrenal hyperplasia (leading to over-production of testosterone) showed an increased frequency of alcohol drinking compared to agematched healthy controls (Falhammar et al., 2014). Two large-scale twin studies showed that the prevalence of hospitalization for AUD in males with male co-twin (interpreted as higher testosterone levels exposure) decreases compared to males with female co-twin (leading to no additional testosterone exposure) (Lenz et al., 2012b). However, this study did not observe similar effect in females regardless of co-twin's sex, possibly because of the insensitivity of outcome measurements used in this study. However, a later study found that females with male co-twin exhibited more lifetime alcohol abuse symptoms than females with female co-twin (Ellingson et al., 2013). Second-to-fourth finger length ratio (2D:4D ratio) is a reliable somatic marker of prenatal exposure to testosterone (Hönekopp et al., 2007). A recent study found that 2D:4D ratio was lower in male patients with alcohol dependence compared with healthy controls (Lenz et al., 2017). These findings imply a relationship between prenatal exposure to excessive testosterone levels and alcohol consumption or alcohol addiction in adults.

Another line of research focuses on investigating the link between testosterone concentrations and alcohol 
consumption in adolescents. Although an early study revealed women with higher testosterone levels were more likely to consume alcohol (A. Martin et al., 1999), later studies found that higher levels of testosterone were reported to be linked to increased alcohol consumption in adolescent males but not in females (Costello et al., 2007; Dolsen et al., 2019; Eriksson et al., 2005). In addition, recent studies revealed that increased testosterone concentrations were also associated with earlier onset of alcohol consumption in adolescent males (de Water et al., 2013) and, predicted a higher risk of subsequent high alcohol consumption in adolescents and young adults (Braams et al., 2016). This influence of testosterone levels on alcohol use has been reported to be modulated by the functional connectivity between amygdala and orbitofrontal cortex, associated with risk taking in the form of increased alcohol intake (Peters et al., 2015). Although the majority of these studies imply a sex-specific effect of testosterone, researchers have recognized the importance of studying females in drug abuse research. There has been an increased scientific interest in illuminating the possible relationship between testosterone levels and alcohol dependence in females during menstrual cycle (Carroll et al., 2015; Erol et al., 2019; Terner and De Wit, 2006). Pre vious studies revealed that females with normal menstrual cycles showed increased frequency/amount of alcohol consumption at menstruation (Joyce et al., 2018), a relationship not present among oral contraceptive users (Sutker et al., 1983). Other research also reported testosterone elevations mediated by alcohol in the postand intermenstrual phases (days 721) (Harvey and Beckman, 1985; Lindman et al., 1999; Schliep et al., 2015).

The findings described above are related to the extent to which testosterone levels affect alcohol consumption. Obviously, the association of testosterone with alcohol consumption is bidirectional. Hence, alcohol consumption may alter testosterone levels during the course of alcohol addiction (Lenz et al., 2012a). Indeed, accumulating evidence in support of alterations to testosterone levels induced by acute and chronic alcohol consumption is found in humans. Early studies found a reduction in testosterone levels following heavy acute alcohol consumption in males (Mendelson et al., 1977), but not in females (Härkönen and Ylikahri, 1983; Mendelson et al., 1981). These results have been confirmed by more recent studies by showing that acute alcohol intoxication (AAI) reduces testosterone levels in male adults (Frias et al., 2002; Sierksma et al., 2004). Interestingly, these effects found in adults could be extended to male adolescents (Diamond Jr et al., 1986; Frias et al., 2000). In addition, more recent studies revealed testosterone elevations after intake of a low dose of alcohol in males (Sarkola and Eriksson, 2003), implying that the impacts of acute al cohol drinking on testosterone levels are dose-dependent. Similarly, many studies have consistently revealed the role of chronic alcohol abuse or alcohol dependence on testosterone levels. Several studies revealed that chronic alcohol abuse decreased testosterone concentrations in men or that men with alcohol dependence had lower levels of testosterone (Gallant, 1989; Maneesh et al., 2006; Muthusami and Chinnaswamy, 2005; Persky et al., 1977). Altogether, to date, all stu dies on the interplay between alcohol use and testosterone levels reveal consistent findings in males in terms of a bidirectional relationship between them. The results in females remain inconclusive.

Alcohol can affect testosterone levels by several different cellular and molecular mechanisms at different sites, from the central nervous system to peripheral organs, including the liver and testes (Rachdaoui and Sarkar, 2017). Thus, consumption of ethanol by alcohol-dependent individuals induces toxic effects leading to hormonal dysregulations (decreases of testosterone and progesterone, increases of estradiol) via the HPG axis causing hypogonadism, decreased fertility and menstrual cycle irregularity (Frias et al., 2002; Rachdaoui and Sarkar, 2017). In the brain, ethanol decreases testosterone by inhibiting enzymes required for its synthesis from its precursor cholesterol, including hydroxysteroid dehydrogenase, oxoreductase and desmolase (Sanna et al., 2016). Furthermore, alcohol consumers and alcohol-dependent individuals can develop liver diseases that will impact the catabolism of steroids including testosterone. In fact, ethanol elevates the activity of aromatase, an enzyme that converts androgens to estrogens, especially in the liver (Purohit, 2000). In addition, ethanol reduces the metabolism of vitamin $A$, such as retinol, which impacts the retinoid homeostasis throughout the body (Clugston and Blaner, 2012). Thus, the levels of retinol and retinoic acid are not only reduced in the liver but also in the testes. Retinoic acid is essential for spermatogenesis and its level is reduced by ethanol that inhibits its synthesis from vitamin A by retinol dehydrogenase 10 enzyme (Tong et al., 2013). Ethanol also directly induces spermatogenic cell apoptosis (Jana et al., 2010). Meanwhile, retinoic acid is 
an essential transcription factor during development and it has been reported recently that alcohol teratogenicity is mediated by the inhibition of the retinoic acid biosynthesis from retinal (Shabtai et al., 2018).

It is important also to pay attention to the constant interplays between neurosteroids, alcohol, $\gamma$ aminobutyric acid type $\mathrm{A}\left(\mathrm{GABA}_{\mathrm{A}}\right.$ ) receptors and, $\mathrm{N}$-methyl-D-aspartate (NMDA) receptors (Helms et al., 2012; Purdy et al., 2005). $G A B A_{A}$ receptors represent major targets for ethanol. $G A B A_{A}$ is an important inhibitory neurotransmitter in the brain. Ethanol increases GABA activity in the brain through (i) the presynaptic neuron that increases GABA release and (ii) the postsynaptic neuron that facilitates the activity of the $G A B A_{A}$ receptors. Ethanol also modulates the $\mathrm{GABA}_{\mathrm{A}}$ receptor activity though an increase of neurosteroid synthesis (Purdy et al., 2005; Sanna et al., 2004). Efficacy of GABA is increased by concentrations of steroids that do not activate the receptors by themselves while others are direct agonists that are able to open the ionic channel of $\mathrm{GABA}_{A}$ receptor in the absence of GABA neurotransmitter (Helms et al., 2012). In different brain regions, it has been observed that neurosteroids enhance the actions of GABA at GABA $A_{A}$ receptors and since ethanol enhances GABA release, these actions are likely to be synergic (Helms et al., 2012).

\subsection{Testosterone AND GAMBLING/GAMBLING BEHAVIOR}

Increasing efforts over the past decade have been directed at investigating the possible association between testosterone levels and gambling behavior (Stenstrom and Saad, 2011). A number of studies have found that testosterone levels are linked to a wide range of gambling-related behavioural phenotypes in healthy subjects, including violent and aggressive behavior in both men and women (Archer et al., 1998; Book et al., 2001; Dabbs and Hargrove, 1997; Dabbs Jr and Morris, 1990; Mehta and Beer, 2010), greater risk taking (Nofsinger et al., 2018; Sapienza et al., 2009; Stanton et al., 2011; van Anders et al., 2012; White et al., 2006) and increased impulsivity (Takahashi et al., 2006). Furthermore, endogenous testosterone levels were correlated with economic risk taking in real life which has been found in the traders from the stock market of London (Coates and Herbert, 2008). Using a proxy of prenatal testosterone exposure (2D:4D ratio), a recent study revealed that such an index could predict risk taking propensity that relates to gambling behavior (Evans and Hampson, 2014). Other studies provide evidence that testosterone levels correlate with risk taking during gambling-related activity in male and female adolescents (de Macks et al., 2016; de Macks et al., 2011). Moreover, these results have been confirmed by more recent studies investigating the role of testosterone administration on gambling behavior. For example, males exhibited elevated impulsive and risky behavior after exogenous testosterone administration compared to the placebo group (Goudriaan et al., 2010; Van Honk et al., 2004; Van Honk et al., 2016; Wu et al., 2019; Wu et al., 2020). However, one study on male college students failed to produce the effects of testosterone using a delay discounting rate task (reflecting impulsive behaviour) (Ortner et al., 2013), possibly because of dose and gender differences (Doi et al., 2015; Wu et al., 2020). Since the relationship between addictive behavior and testosterone levels is bidirectional, another line of research has studied the influence of gambling behavior on testosterone levels. A study found that testosterone significantly increased during a one-on-one poker competition, while outcomes of the gambling competition did not affect testosterone levels (Steiner et al., 2010). A more recent study not only supports these findings, but also suggests that such effects could be extended into a slot machine gambling task in healthy male subjects (Ferrari et al., 2018). Taken together, these results clearly suggest that increased levels of testosterone in healthy subjects are related to higher risk taking or to higher impulsive propensity that relate to gambling behavior. At the same time engaging in gambling-related activity modulates testosterone levels in healthy subjects.

Given the fact that increased impulsivity and risk taking have been proposed as good predictive markers for gambling addiction (Bodor et al., 2016; Verdejo-García et al., 2008), the association between circulating testosterone levels and impulsive and risky behavior in healthy subjects implies the hormonal underpinning of these behavioural problems. Blanco et al., (2001) reported the first empirical study directly comparing basal testosterone levels between gambling disorders and age/gender matched healthy controls (Blanco et al., 2001). They found that there was no significant between-group difference in basal testosterone levels and that 
testosterone levels did not correlate with personality traits such as neuroticism and extroversion measured by the Eysenck Personality Questionnaire (Eysenck and Eysenck, 1975). Aside from this study, surprisingly, no other research has directly investigated potential interactions between testosterone and gambling behavior in a sample of individuals with gambling disorders. Based on animal model experiments with adapted IGT showing the effect of testosterone levels in the decision making and in its altered phenotype (Wallin-Miller et al., 2018), it is tempting to speculate on the cellular and molecular pathophysiological mechanisms regulated by elevated levels of testosterone and, likely other neurosteroids. They may impact the brain neurotransmission, especially via the GABAergique system. Interestingly, it has been shown recently that subjects with problem gambling present a reduced dopamine induced GABA release, supporting a possible contribution to a loss of inhibitory control, reported by the clinical assessment of subjects (Møller et al., 2019).

In summary, accumulating evidence points to the positive relationship between testosterone levels and risk taking or impulsive propensity that relate to gambling behavior in samples of healthy subjects. Moreover, testosterone administration could increase gambling proneness and in turn, there is an increase in testosterone concentrations during gambling. However, the knowledge about the interplay between gambling behavior and testosterone is very limited in individuals with a gambling addiction.

\subsection{SIMILARITIES AND differences REGARDING testosterone in ALCOHOL use/ dependence vs. GAMBLING/GAMBLING disorders}

The empirical findings described above indicate that increased testosterone levels are related to increased alcohol use in healthy subjects, mainly in male adults and adolescents. Higher testosterone levels correlate positively with greater risk taking or increased impulsivity in alcohol consumption in men, thereby increasing vulnerability to al cohol addiction. Meanwhile, acute alcohol drinking significantly suppressed testosterone levels mainly in males, and such effects are dosedependent. Furthermore, previous studies have revealed that chronic alcohol consumption decreased testosterone levels in alcohol-dependent males. These studies not only suggest a sex-specific effects of testosterone on alcohol consumption, but also show blunted testosterone responses to acute or chronic alcohol consumption. Similarly, with respect to gambling addiction, prior studies found a similar relationship between testosterone levels and gambling behavior in healthy subjects. High testosterone levels are associated with increased risk taking or impulsive dispositions that relate to gambling behavior. Accordingly, most results support a relationship between high levels of testosterone and increased alcohol consumption or gambling behavior in healthy subjects (Fig. 2). In contrast, differences in the link between testosterone concentrations and alcohol abuse or gambling behavior have been found between gambling disorder and alcohol-dependent individuals (Fig. 2). Although a significant between-group difference in testosterone levels is observed in alcohol-dependent individuals in terms of reduced testosterone levels, to date, previous studies failed to find similar effects in gambling disorders (Blanco et al., 2001). In addition, previous studies on alcohol addiction support sex-specific effects of testosterone on alcohol consumption, whereas we can not draw similar conclusions on gambling disorders based on the literature available in the field. However, the behaviour of risk-taking, observed in both gambling disorder and AUDs, is clearly correlated with the level of testosterone, as well as cortisol and the gender of the individuals (Barel et al., 2017). Thus, a significant higher testosterone/cortisol ratio is related to a higher risk-taking in males while an opposite correlation is observed in females (Barel et al., 2017). This observation and previous cited works on decision making suggest that testosterone, and likely other neurosteroids, from the HPG axis, with the participation of other endocrine modulators from the HPA axis, may act in the same manner in both alcohol use and gambling behavior.

To summarize, evidence suggests a relationship between high levels of testosterone and both increased alcohol consumption and elevated gambling behavior. In contrast, reduced testosterone levels are found in alcohol-dependent individuals, whereas no between-group differences in testosterone levels in gambling disorders are observed. In addition, the interplay between testosterone levels and alcohol consumption or alcohol addiction is sex-specific, while not enough evidence supports such effects in gambling disorders.

3. Cortisol in alcohol use/dependence and gambling disorders 
Over the past decades, accumulating evidence clearly demonstrates a dynamic interplay between the functioning of the HPA axis and alcohol use and dependence (Blaine and Sinha, 2017; Uhart and Wand, 2009; Wemm and Sinha, 2019). In healthy population samples, a relationship between cortisol secretion and alcohol consumption has been reported. A few epidemiological and longitudinal studies found increased cortisol levels in heavy drinkers, especially in males (Badrick et al., 2008; Gianoulakis et al., 2003) and in adolescents (Ruttle et al., 2015). These findings have been corroborated by other recent studies showing a positive relationship between cortisol levels and units of alcohol use per week in male heavy drinkers and an increased cortisol awakening response in female heavy drinkers (Badrick et al., 2008). Moreover, this association is dependent on alcohol cue contexts in heavy drinkers, thereby modulating their behavioural motivation for alcohol (Blaine et al., 2019). These findings suggest that alcohol use is related to the activation of the HPA axis in non-dependent users and may imply chronic changes to the HPA axis in chronic drinking individuals. Some researchers argued that such an association was possibly driven by the role of acute stressors in the motivation for alcohol use (Goeders, 2004; Sinha, 2001; Sinha and O'Malley, 1999; Stephens and Wand, 2012). A wealth of preclinical and clinical data generally support that acute exposure to stress increases the vulnerability to alcohol abuse and craving (Amlung and MacKillop, 2014; Bibbey et al., 2015; Breese et al., 2005; Breese et al., 2011; Chaplin et al., 2008; Childs et al., 2011; de Wit et al., 2003; Magrys and Olmstead, 2015; Serre et al., 2015). In addition, increasing efforts have also been devoted into investigating effects of alcohol use in humans. Acute alcohol consumption has been demonstrated to consistently stimulate the HPA axis and increase cortisol levels in non-dependent alcohol users (Allen et al., 2011; Childs et al., 2011; Frias et al., 2000; Gianoulakis et al., 1996; Magrys et al., 2013; Mendelson and Stein, 1966; Sarkola et al.,1999; Välimäki et al., $1984 a)$. Frequent, heavy alcohol use dysregulates the HPA axis in these non-dependent alcohol consumers. The data generally support the notion that basal cortisol levels increase in both male heavy drinkers (Thayer et al., 2006) and female heavy drinkers (Wemm et al., 2013). Moreover, other evidence also found that increases in cortisol levels induced by alcohol consumption were attenuated in heavy compared to light/moderate social drinkers (King et al., 2006; Orio et al., 2018), possibly because of a blunted cortisol response to alcohol in those who were heavy consumers.

On the other hand, alterations of the HPA functioning in alcoholdependent users were also found. Evidence suggests elevated cortisol levels in alcohol-dependent individuals (Adinoff et al., 2003; Bertello et al., 1982). Furthermore, cortisol levels tend to be elevated during periods of heavy intake in alcohol-dependent patients (Wand and Dobs, 1991). Abstaining from alcohol consumption and during withdrawal, individuals with alcohol dependence showed elevated basal cortisol levels (Errico et al., 2002; Mendelson et al., 1966; Starcke et al., 2013; Välimäki et al., 1990; Walter et al., 2006b), and reduced diurnal secretion pattern (Ravitz and Nutt, 1991). However, longer abstinence reduced basal cortisol levels (Motaghinejad et al., 2015). In line with these findings, those who were alcoholics have been consistently shown to have blunted cortisol responses to both physical and psychological stressors (Bernardy et al., 1996; Errico et al., 1993; Muehlhan et al., 2018; Wand and Dobs, 1991).

Collectively, these findings support that alcohol acutely enhances activity of the HPA axis in individuals without alcohol dependence and may therefore dysregulate the stress response to a stressor. In addition, these reports also point to neuroadaptations in the HPA response in individuals with heavy, chronic use and alcohol dependence resulting in a blunted phasic response but elevated tonic levels relative to healthy controls.

\subsection{Cortisol in GAMBLING/GAMBLING disorders}

Over the past decade, a wealth of evidence points to a relationship between basal cortisol levels and impulsivity or risk taking dispositions in healthy subjects. There is evidence showing a significant negative association between basal cortisol levels and time-discounting rate of monetary gains in males 
(Takahashi, 2004). This suggests that individuals with low cortisol levels tend to be more impulsive in intertemporal choice. Other research also revealed a negative correlation between levels of cortisol and risky choices in a gambling task (van Honk et al., 2003). Those with low levels of cortisol adopting a disadvantageous pattern of risky decision making. These findings indicate a relationship between low levels of cortisol and impulsive or risk taking dispositions that relate to gambling behaviour in healthy subjects, which may underpin a predisposition towards gambling disorders. Indeed, recent evidence seems to support this argument by showing a negative correlation between cortisol levels and gambling severity in individuals with gambling disorders (Geisel et al., 2015). In addition to such correlative evidence, another line of research put an emphasis on the interplay between cortisol and gambling behavior in healthy subjects and gambling-addicted individuals. Regarding the effects of gambling on cortisol secretion, several studies found that cortisol increased during casino gambling (blackjack) in male subjects without gambling addiction relative to control conditions (Krueger et al., 2005; Meyer et al., 2000). Thus a similar effect might contribute to the development of gambling addiction. Indeed, an early study supports this notion by showing a relationship between basal cortisol levels and psychological measures in pathological gamblers (Ramirez et al., 1988). In individuals with gambling disorders, an early study found that pathological gamblers showed increased cortisol production compared to baseline values throughout gambling sessions and there was a significant between-group difference (Meyer et al., 2004). Another study also found elevated cortisol levels throughout the gambling sessions, but did not find between-group differences (Labudda et al., 2007).

However, more recent studies highlight sex differences in cortisol levels in response to gambling stimuli in gamblers (a larger effect in males) (Franco et al., 2010; Paris et al., 2010a). In addition to effects of gambling stimulation on cortisol levels, there are some studies attempting to investigate the impacts of acute stressors on the functioning of the HPA axis in individuals with gambling disorders. An early study showed a hypoactive HPA response to acute stressors induced by watching a video of gambling activity in pathological gamblers compared to recreational gamblers, regardless of gender (Paris et al., 2010b), while more recent studies failed to find a difference in the HPA response to social stress between individuals with gambling disorders and healthy controls (Arshad, 2018; Maniaci et al., 2018; Wemm et al., 2018). Since gambling itself can act as a stressor and has stress-like physiological effects (Buchanan et al., 2020), such evidence may indicate that effects of stress on the HPA response in gambling-addicted individuals is relatively specific to stressful events associated with gambling activity. Moreover, surprisingly, these studies did not find any significant difference in basal cortisol levels between compulsive gamblers and healthy controls. This observation has been corroborated by a recent brain imaging study (Li et al., 2014). Although no betweengroup differences were observed in basal levels of cortisol, levels of cortisol were found to be positively correlated with ventral striatal responses to monetary vs. erotic cues in gamblers, but not in healthy controls. This finding may imply that the association between cortisol levels and motivational bias towards gambling-related stimuli reflects an effort to restore homeostasis from allostasis caused by chronic exposure to gambling (a stressful event) in individuals with gambling disorders, as discussed in a recent review (Biback and Zack, 2015).

\subsection{SIMILARITIES AND differences REGARDING cortisol in ALCOHOL use/ dependence vs. GAMBLING disorders}

Empirical studies have consistently revealed a link between basal cortisol levels and alcohol consumption or gambling proneness in healthy subjects. However, the direction of such an association is somewhat different in alcohol use vs. gambling behavior (Fig. 3). There is a positive association between basal levels of cortisol and alcohol consumption in both light and heavy drinkers, whereas there is a negative relationship between basal cortisol levels and risk taking or impulsive propensities that relate to gambling behavior in healthy subjects or gambling severity/duration in individuals with gambling disorders. These opposing patterns of relationships between nonsubstance vs. substance abuse make opposing predictions concerning vulnerability to addiction. Individuals with high cortisol levels are at high risk of alcohol abuse, while those with low cortisol levels are at high risk of developing gambling 
addictions.

In addition, evidence from these two lines of research suggest commonalities in the effects of alcohol consumption or gambling stimulation with respect to cortisol secretion. Alcohol intake or engaging in gambling increased cortisol levels in both healthy subjects and ad dicts. Although there is evidence to show that such effects are dosedependent for alcohol consumption, no such evidence is available in the field of gambling studies. Individuals with alcohol dependence and gambling disorders show blunted cortisol responses to stressors, indicating alterations to the activity of HPA axis in nonsubstance and substance addicts. However, those who were alcohol dependent also showed high tonic cortisol levels and a blunted phasic cortisol response to stressors, whereas little is known about such aspects of cortisol response in gambling disorders. Furthermore, basal cortisol levels are elevated in alcohol-dependent individuals relative to healthy controls (Blaine and Sinha, 2017), while no such between-group differences are observed in those with gambling disorders. Another aspect that should be taken into account is the gender of the individuals. The level of cortisol, as well as, the answer to a stress are different between men and women. Furthermore, both resting level of cortisol and the response to a stress change depending of the stage of estrous cycle. Cortisol levels modulate the decision making and, in particular the risky behaviour. It has been shown in human and in animal models that males are more risk-prone than females, or have less aversion to the risk than females. Furthermore, it has been demonstrated as tasks progress, males but not females, increase their preference for advantageous options, thus improving their overall performance and net gain (Georgiou et al., 2018; Van den Bos et al., 2009).

The research showing blunted HPA activation in substance use disorders leads to the question of whether the difference of HPA function is a consequence of addiction or a characteristic of the people. In fact, a hyporesponsive HPA indicates the gravity of the addictive process. AUD patients harboring lower cortisol responses to public speaking stress relapse more rapidly under treatment (Junghanns et al., 2003). The same observation was reported when the cortisol response was measured in a cue exposure procedure with responses to alcohol cues (Junghanns et al., 2004). Interestingly, works on abstinent smokers show that lower cortisol responses to stressors harbor also a greater relapse potential (Al'absi, 2006). Furthermore, lower tonic cortisol levels were observed in smokers presenting a higher relapse probability (Steptoe and Ussher, 2006). Finally, AUDs and gambling behavior may partly result from a common neurocognitive default due to a maladaptive decision making modulated by stress and cortisol.

\section{Limitations of current knowledge}

Based on the description above, most of the data currently available demonstrate neuroendocrine changes accompanying excessive substance use (e.g., alcohol consumption) and excessive behaviours (such as gambling). Such an association between neuroendocrine changes and addictive-related behaviour provides important clues to the nature of changes occurring as a result of the substance or nonsubstance use associated with vulnerability to addiction and addiction. Data concerning the involvement of the HPA system is far more coherent for both substance and nonsubstance use disorders. Nevertheless, this review also indicates potential limitations in contemporary knowledge about the relationships between hormonal changes and alcohol use or gambling. Firstly, even though the majority of investigations on alcohol use/ misuse have been conducted in men, there is an increasing number of

studies supporting the existence of gender differences in several aspects of such behaviour (Agabio et al., 2017; Becker and Hu, 2008; Erol and Karpyak, 2015). Gender-related differences in alcohol consumption have long been attributed to some psychosocial factors (e.g., personality traits such as impulsivity and risk taking) (Cook et al., 1998; Nolen-Hoeksema and Hilt, 2006). Although social and cultural expectations for alcohol consumption between the sexes differ, biological differences between men and women could play an important role in these behavioural differences. One important biological difference between sex involves sex hormones such as testosterone, which have been argued to account partly for different motives to consume alcohol between the sexes (Erol et al., 2019; Rosanna et al., 2016). In contrast, although similar psychosocial factors have been found to play an important role in gender-related differences in some aspects of gambling 
behaviour (LaBrie et al., 2007), the possible contribution of hormonal factors to such differences in gambling behaviour is very limited (Sapienza et al., 2009). As such, we believe that an increase in knowledge of hormonal influences contributing to different motives to consume alcohol or gamble between the sexes suggests the need to perform studies recruiting adequate numbers of women with gambling disorders. This will undoubtedly advance our understanding of behavioural addictions, especially in relation to personality traits such as impulsivity and risk taking that are central to the development of gambling -behaviour.

Secondly, despite remarkable progress on examining the dynamic interplay between testosterone levels and alcohol consumption or gambling -behaviour in alcohol or gambling addiction, the potential link between circadian rhythms of testosterone concentrations and these addictive -behaviours seems to be neglected. The testosterone diurnal patterns have been shown to be highest in the morning hours and lowest in the evening hours in healthy individuals (Kraemer et al., 2001; Passelergue et al., 1995). Moreover, there are age-related alterations in the circadian rhythms of testosterone secretions characterized by a decrease in testosterone levels and the loss of its circadian rhythmicity with normal aging (Bremner et al., 1983; Copinschi and Van Cauter, 1995; Richardson, 1990; Tenover et al., 1988; Touitou, 1995; Touitou and Haus, 2000). Although altered testosterone diurnal patterns have been found to occur in relation to some psychiatric and neurological diseases (Collomp et al., 2016), such as schizophrenia (Taherianfard and Shariaty, 2004) and Parkinson's disease (Nitkowska et al., 2015; Ready et al., 2004), only early preliminary studies have investigated possible alterations in such circadian rhythmicity in male alcoholics (Bertello et al., 1982; Välimäki et al., 1984b). More importantly, to our knowledge, the circadian rhythm of testosterone has not been investigated in gambling disorders. To deepen our understanding of the contribution of hormonal factors to alcohol and gambling addiction, this requires future studies on the link between testosterone circadian rhythm and these kinds of addictive disorders and how age modulates such a potential link.

Last but not the least, interest in the potential link between gambling and mood states from gamblers or alcoholics has increased. Previous studies have found that gambling leads to changes in levels of subjective mood state (Dickerson and Adcock, 1987; Gee et al., 2005; Mishra et al., 2010). More importantly, mood states influence individuals' risky decisions in gambling tasks (Buelow and Suhr, 2013) and can act as predictors of problem gambling (Matthews et al., 2009). It has also been found that the need to regulate mood states contributes to persistent gambling in gambling disorders (Goldstein et al., 2014; Griffiths, 1995; Lloyd et al., 2010). Similarly, alcohol consumption has been found to be associated with lower levels of nervousness (Swendsen et al., 2000) and elevated moods (Freed, 1978). At the same time, recent evidence has further revealed that mood states can also act as predictors of alcohol use and problems (Hogarth et al., 2018; Stevenson et al., 2019). On the other hand, affective states are known to be regulated by testosterone (Van Wingen et al., 2011) and mood dysregulation has long been associated with HPG axis dysfunction (Toren et al., 1996). Meanwhile, cortisol has been found to be associated with anxiety or depressive symptoms in mood disorders (Forsythe et al., 2010). All together, these data seem to indicate a possible mediating role of mood states in the relation between these two hormones and alcohol or gambling problems, which may promote vulnerability to these two addictive disorders. Direct evidence supporting this is a subject for future studies..

\section{Future research considerations}

In addition to those aspects described above, the following research directions may be considered in future studies.

Firstly, regarding treatment studies, findings from alcohol use/dependence and gambling disorders collectively suggest that altered functioning of the HPA and HPG axes may serve as a target for the investigation of therapeutic interventions and a marker to evaluate prevention efforts (Greenwald, 2018; Milivojevic and Sinha, 2018). The prevention cares targeted at individuals with risk factors known to modulate the sex hormone system and the stress system (including early life experience, genetics, family education and environment) may decrease the likelihood that they will develop a substance or nonsubstance use disorder. Furthermore, with regard to treatment cares for those with addictive disorders, understanding the commonalities and differences in the neuroadaptations of HPG and HPA axes between substance and 
nonsubstance addiction may provide clinically valuable informa tion for deciphering how treatments act, especially for understanding for whom specific therapeutics work best for each type of addictive disorder.

Secondly, other research directions may be taken into account by future studies searching the interplay between testosterone concentrations and alcohol use or gambling abuse. Regardless of addictive disorders, in human studies, females with menarche history or oestrus phase should be considered. Similarly, the possible role of potential confounders, such as oral contraception, need also to be considered. More importantly, very few studies attempted to explore the interplay between testosterone levels and gambling disorders, especially at different stages of gambling addiction. Apart from studying testosterone roles during various developmental stages, the consideration of other phases, including the periods of prolonged abstinence to gambling addiction, will help to investigate the relationship between testosterone levels and propensity to relapse. This may shed light on treatment design.

Finally, with the development of research on the interplay between the HPG or HPA systems and addictiverelated behaviours, this may require future larger replication studies and meta-analyses to confirm the observed findings.

\section{Conclusions}

Despite that the research on gambling disorders is in its infancy, the contemporary evidence supports a positive association of testosterone levels with both increased alcohol consumption and gambling behavior in humans. However, reduced testosterone levels are found in alcoholdependent individuals, whereas no between-group differences in testosterone levels in gambling disorders are observed. In addition, the interplay between testosterone levels and alcohol consumption or alcohol addiction is sex-specific, whereas there is insufficient evidence to determine whether this is the case in gambling disorders. Similar to testosterone, cortisol levels have been linked to alcohol consumption or gambling proneness in previous studies. However, the direction of such an association is somewhat different in alcohol use vs. gambling behaviour. Further research that includes both sexes, mood states and circadian patterns is needed to elucidate the complex interplay between these two hormones and substance use disorders and nonsubstance addictions. This is necessary to deepen the understanding of similarities and differences between these two kinds of addictive disorders and for the development of appropriate health policies.

\section{References}

Adinoff, B., Ruether, K., Krebaum, S., Iranmanesh, A., Williams, M.J., 2003. Increased salivary cortisol concentrations during chronic alcohol intoxication in a naturalistic clinical sample of men. Alcohol. Clin. Exp. Res. 27 (9), 1420-1427.

Agabio, R., Pisanu, C., Luigi Gessa, G., Franconi, F., 2017. Sex differences in alcohol use disorder. Curr. Med. Chem. 24 (24), 2661-2670.

Al'absi, M., 2006. Hypothalamic-pituitary-adrenocortical responses to psychological stress and risk for smoking relapse. Int. J. Psychophysiol. 59 (3), 218-227.

Alavi, S.S., Ferdosi, M., Jannatifard, F., Eslami, M., Alaghemandan, H., Setare, M., 2012. Behavioral addiction versus substance addiction: correspondence of psychiatric and psychological views. Int. J. Prev. Med. 3 (4), 290.

Alhadeff, A.L., Goldstein, N., Park, O., Klima, M.L., Vargas, A., Betley, J.N., 2019. Natural and drug rewards engage distinct pathways that converge on coordinated hypotha- lamic and reward circuits. Neuron 103 (5), 891-908.

Allen, C.D., Rivier, C.L., Lee, S.Y., 2011. Adolescent alcohol exposure alters the central brain circuits known to regulate the stress response. Neuroscience 182, 162-168.

Amlung, M., MacKillop, J., 2014. Understanding the effects of stress and alcohol cues on motivation for alcohol via behavioral economics. Alcohol. Clin. Exp. Res. 38 (6), 1780-1789.

Archer, J., Birring, S.S., Wu, F.C., 1998. The association between testosterone and ag-gression among young men: empirical findings and a meta-analysis. Aggress. Behav. 24 (6), 411-420. 
Arshad, F., 2018. Acute Psychosocial Stress Reactivity and Risky Decision-Making in Gambling Disorder.

Association, A.P, 2013. Diagnostic and statistical manual of mental disorders. BMC Med.

17, 133-137.

Badrick, E., Bobak, M., Britton, A., Kirschbaum, C., Marmot, M., Kumari, M., 2008. The relationship between alcohol consumption and cortisol secretion in an aging cohort.

J. Clin. Endocrinol. Metab. 93 (3), 750-757.

Barel, E., Shahrabani, S., Tzischinsky, O., 2017. Sex hormone/cortisol ratios differentially modulate risk-taking in men and women. Evol. Psychol. 15 (1), 1474704917697333. Bawor, M., Bami, H., Dennis, B.B., Plater, C., Worster, A., Varenbut, M., Daiter, J., Marsh, D.C., Steiner, M., Anglin, R., Coote, M., Pare, G., Thabane, L., Samaan, Z., 2015. Testosterone suppression in opioid users: a systematic review and meta-analysis. Drug Alcohol Depend. 149, 1-9.

Becker, J.B., Hu, M., 2008. Sex differences in drug abuse. Front. Neuroendocrinol. 29 (1), 36-47.

Bernardy, N.C., King, A.C., Parsons, O.A., Lovallo, W.R., 1996. Altered cortisol response in sober alcoholics: an examination of contributing factors. Alcohol 13 (5), 493-498. Bertello, P., Agrimonti, F., Gurioli, L., Frairia, R., Fornaro, D., Angeli, A., 1982. Circadian patterns of plasma cortisol and testosterone in chronic male alcoholics.

Exp. Res. 6 (4), 475-481.

Alcohol. Clin.

Biback, C., Zack, M., 2015. The relationship between stress and motivation in patholo-gical gambling: a focused review and analysis. Curr. Addict. Rep. 2 (3), 230-239.

Bibbey, A., Phillips, A.C., Ginty, A.T., Carroll, D., 2015. Problematic internet use, ex- cessive alcohol consumption, their comorbidity and cardiovascular and cortisol re-actions to acute psychological stress in a student population. J. Behav. Addict. 4 (2), 44-52.

Blaine, S.K., Sinha, R., 2017. Alcohol, stress, and glucocorticoids: from risk to dependence and relapse in alcohol use disorders. Neuropharmacology 122, 136-147.

Blaine, S.K., Nautiyal, N., Hart, R., Guarnaccia, J., Sinha, R., 2019. Craving, cortisol and

behavioral alcohol motivation responses to stress and alcohol cue contexts and dis-crete cues in binge and non-binge drinkers. Addict. Biol. 24 (5), 1096-1108.

Blanco, C., Ibáñez, A., Blanco-Jerez, C.-R., Baca-Garcia, E., Sáiz-Ruiz, J., 2001. Plasma testosterone and pathological gambling. Psychiatry Res. 105 (1-2), 117-121.

Blum, K., Braverman, E.R., Holder, J.M., Lubar, J.F., Monastra, V.J., Miller, D., Lubar, J.O., Chen, T.J., Comings, D.E., 2000. The reward deficiency syndrome: a biogenetic model for the diagnosis and treatment of impulsive, addictive and compulsive be- haviors. J. Psychoactive Drugs 32 (sup1), 1-112.

Bodor, D., Tomić, A., Ricijaš, N., Filipčić, I., 2016. Impulsiveness in alcohol addiction and pathological gambling. Alcohol Psychiatry Res. 52 (2), 149-158.

Book, A.S., Starzyk, K.B., Quinsey, V.L., 2001. The relationship between testosterone and aggression: a metaanalysis. Aggress. Violent Behav. 6 (6), 579-599.

Braams, B.R., Peper, J.S., Van Der Heide, D., Peters, S., Crone, E.A., 2016. Nucleus ac- cumbens response to rewards and testosterone levels are related to alcohol use in adolescents and young adults. Dev. Cogn. Neurosci. 17, 83-93.

Breese, G.R., Chu, K., Dayas, C.V., Funk, D., Knapp, D.J., Koob, G.F., Lê, D.A., O’Dell, L.E., Overstreet, D.H., Roberts, A.J., 2005. Stress enhancement of craving during sobriety: a risk for relapse. Alcohol. Clin. Exp. Res. 29 (2), 185-195.

Breese, G.R., Sinha, R., Heilig, M., 2011. Chronic alcohol neuroadaptation and stress contribute to susceptibility for alcohol craving and relapse. Pharmacol. Ther. 129 (2), 149-171.

Bremner, W.J., Vitiello, M.V., Prinz, P.N., 1983. Loss of circadian rhythmicity in blood testosterone levels with aging in Normal men*. J. Clin. Endocrinol. Metab. 56 (6), 1278-1281.

Buchanan, T.W., McMullin, S.D., Baxley, C., Weinstock, J., 2020. Stress and gambling. Curr. Opin. Behav. Sci. 31, 8-12.

Buelow, M.T., Suhr, J.A., 2013. Personality characteristics and state mood influence in- dividual deck selections on the lowa gambling task. Personal. Individ. Differ. 54 (5), 593-597.

Carroll, H.A., Lustyk, M.K.B., Larimer, M.E., 2015. The relationship between alcohol consumption and menstrual cycle: a review of the literature. Arch. Womens Mental Health 18 (6), 773-781.

Chaplin, T.M., Hong, K., Bergquist, K., Sinha, R., 2008. Gender differences in response to emotional stress: an assessment across subjective, behavioral, and physiological do- mains and relations to alcohol craving. Alcohol. Clin. Exp. Res. 32 (7), 1242-1250. Childs, E., O'Connor, S., de Wit, H., 2011. 
Bidirectional interactions between acute psychosocial stress and acute intravenous alcohol in healthy men. Alcohol. Clin. Exp. Res. 35 (10), 1794-1803.

Choi, S.-W., Kim, H., Kim, G.-Y., Jeon, Y., Park, S., Lee, J.-Y., Jung, H., Sohn, B., Choi, J.- S., Kim, D.-J., 2014. Similarities and differences among internet gaming disorder, gambling disorder and alcohol use disorder: a focus on impulsivity and compulsivity. J. Behav. Addict. 3 (4), 246-253.

Clugston, R.D., Blaner, W.S., 2012. The adverse effects of alcohol on vitamin a metabo- lism. Nutrients 4 (5), 356-371.

Coates, J.M., Herbert, J., 2008. Endogenous steroids and financial risk taking on a London trading floor. Proc. Natl. Acad. Sci. 105 (16), 6167-6172.

Collomp, K., Baillot, A., Forget, H., Coquerel, A., Rieth, N., Vibarel-Rebot, N., 2016.

Altered diurnal pattern of steroid hormones in relation to various behaviors, external factors and pathologies: a review. Physiol. Behav. 164, 68-85.

Contreras-Rodríguez, O., Albein-Urios, N., Vilar-López, R., Perales, J.C., Martínez- Gonzalez, J.M., FernándezSerrano, M.J., Lozano-Rojas, O., Clark, L., Verdejo-García, A., 2016. Increased corticolimbic connectivity in cocaine dependence versus patho- logical gambling is associated with drug severity and emotion-related impulsivity. Addict. Biol. 21 (3), 709-718.

Cook, M., Young, A., Taylor, D., Bedford, A.P., 1998. Personality correlates of alcohol consumption. Personal. Individ. Differ. 24 (5), 641-647.

Copinschi, G., Van Cauter, E., 1995. Effects of ageing on modulation of hormonal se- cretions by sleep and circadian rhythmicity. Hormones 43 (1-3), 20-24.

Costello, E.J., Sung, M., Worthman, C., Angold, A., 2007. Pubertal maturation and the development of alcohol use and abuse. Drug Alcohol Depend. 88, S50-S59.

Dabbs, J., Hargrove, M.F., 1997. Age, testosterone, and behavior among female prison inmates. Psychosom. Med. 59 (5), 477-480.

Dabbs Jr., J.M., Morris, R., 1990. Testosterone, social class, and antisocial behavior in a sample of 4,462 men. Psychol. Sci. 1 (3), 209-211.

Dallman, M.F., Akana, S.F., Levin, N., Walker, C.D., Bradbury, M.J., Suemaru, S., Scribner, K.S., 1994. Corticosteroids and the Control of Function in the Hypothalamo- Pituitary-Adrenal (HPA) Axis a. Annals of the New York Academy of Sciences. 746(1). pp. 22-31.

de Macks, Z.A.O., Moor, B.G., Overgaauw, S., Güroğlu, B., Dahl, R.E., Crone, E.A., 2011. Testosterone levels correspond with increased ventral striatum activation in response to monetary rewards in adolescents. Dev Cogn. Neurosci. 1 (4), 506-516.

de Macks, Z.A.O., Bunge, S.A., Bell, O.N., Wilbrecht, L., Kriegsfeld, L.J., Kayser, A.S., Dahl, R.E., 2016. Risky decision-making in adolescent girls: the role of pubertal hormones and reward circuitry. Psychoneuroendocrinology 74, 77-91.

de Water, E., Braams, B.R., Crone, E.A., Peper, J.S., 2013. Pubertal maturation and sex steroids are related to alcohol use in adolescents. Horm. Behav. 63 (2), 392-397.

de Wit, H., Söderpalm, A.H., Nikolayev, L., Young, E., 2003. Effects of acute social stress on alcohol consumption in healthy subjects. Alcohol. Clin. Exp. Res. 27 (8), 1270-1277.

Diamond Jr., F., Ringenberg, L., Macdonald, D., Barnes, J., Hu, C.S., Duckett, G., Sweetland, M., Root, A., 1986. Effects of drug and alcohol abuse upon pituitary- testicular function in adolescent males. J. Adolesc. Health Care 7 (1), 28-33.

Dickerson, M., Adcock, S., 1987. Mood, arousal and cognitions in persistent gambling: preliminary investigation of a theoretical model. J. Gambl. Behav. 3 (1), 3-15.

Doi, H., Nishitani, S., Shinohara, K., 2015. Sex difference in the relationship between salivary testosterone and inter-temporal choice. Horm. Behav. 69, 50-58.

Dolsen, M.R., Deardorff, J., Harvey, A.G., 2019. Salivary pubertal hormones, sleep dis- turbance, and an evening circadian preference in adolescents: risk across health domains. J. Adolesc. Health 64 (4), 523-529.

Ellingson, J.M., Slutske, W.S., Richmond-Rakerd, L.S., Martin, N.G., 2013. Investigating the influence of prenatal androgen exposure and sibling effects on alcohol use and alcohol use disorder in females from opposite-sex twin pairs. Alcohol. Clin. Exp. Res. 37 (5), 868-876.

Eriksson, C.P., Kaprio, J., Pulkkinen, L., Rose, R.J., 2005. Testosterone and alcohol use among adolescent male twins: testing between-family associations in within-family comparisons. Behav. Genet. 35 (3), 359-368. 
Erol, A., Karpyak, V.M., 2015. Sex and gender-related differences in alcohol use and its consequences: contemporary knowledge and future research considerations. Drug Alcohol Depend. 156, 1-13.

Erol, A., Ho, A.M.C., Winham, S.J., Karpyak, V.M., 2019. Sex hormones in alcohol con- sumption: a systematic review of evidence. Addict. Biol. 24 (2), 157-169.

Errico, A.L., Parsons, O.A., King, A.C., Lovallo, W., 1993. Attenuated cortisol response to biobehavioral stressors in sober alcoholics. J. Stud. Alcohol 54 (4), 393-398.

Errico, A.L., King, A.C., Lovallo, W.R., Parsons, O.A., 2002. Cortisol dysregulation and cognitive impairment in abstinent male alcoholics. Alcohol. Clin. Exp. Res. 26 (8), 1198-1204.

Evans, K.L., Hampson, E., 2014. Does risk-taking mediate the relationship between tes- tosterone and decisionmaking on the lowa gambling task? Personal. Individ. Differ. 61, 57-62.

Eysenck, H.J., Eysenck, S.B.G., 1975. Manual of the eysenck personality questionnaire (junior and adult). In: Hodder and Stoughton.

Falhammar, H., Butwicka, A., Landén, M., Lichtenstein, P., Nordenskjöld, A., Nordenström, A., Frisén, L., 2014. Increased psychiatric morbidity in men with congenital adrenal hyperplasia due to 21-hydroxylase deficiency. J. Clin. Endocrinol. Metab. 99 (3), E554-E560.

Ferrari, M.A., Chan, M., Brown, P.N., Clark, L., 2018. Slot machine gambling and tes-tosterone: evidence for a "winner-loser" effect? Psychol. Addict. Behav. 32 (8), 961.

Forsythe, P., Sudo, N., Dinan, T., Taylor, V.H., Bienenstock, J., 2010. Mood and gut feelings. Brain Behav. Immun. 24 (1), 9-16.

Franco, C., Paris, J., Wulfert, E., Frye, C., 2010. Male gamblers have significantly greater salivary cortisol before and after betting on a horse race, than do female gamblers. Physiol. Behav. 99 (2), 225-229.

Frascella, J., Potenza, M., Brown, L., Childress, A., 2010. Shared brain vulnerabilities open the way for nonsubstance addictions: carving addiction at a new joint? In: Annals of the New York Academy of Sciences. 1187. pp. 294-315.

Freed, E.X., 1978. Alcohol and mood: an updated review. Int. J. Addict. 13 (2), 173-200.

Frias, J., Rodriguez, R., Torres, J., Ruiz, E., Ortega, E., 2000. Effects of acute alcohol intoxication on pituitarygonadal axis hormones, pituitary-adrenal axis hormones, $\beta$ - endorphin and prolactin in human adolescents of both sexes. Life Sci. 67 (9), 1081-1086.

Frias, J., Torres, J., Miranda, M., Ruiz, E., Ortega, E., 2002. Effects of acute alcohol in- toxication on pituitarygonadal axis hormones, pituitary-adrenal axis hormones, $\beta$ - endorphin and prolactin in human adults of both sexes. Alcohol Alcohol. 37 (2), 169-173.

Gallant, D.M., 1989. Chronic alcoholism and low testosterone levels. Alcohol. Clin. Exp. Res. 13 (5), 721.

Gee, P., Coventry, K.R., Birkenhead, D., 2005. Mood state and gambling: using mobile telephones to track emotions. Br. J. Psychol. 96 (1), 53-66.

Geisel, O., Panneck, P., Hellweg, R., Wiedemann, K., Müller, C.A., 2015. Hypothalamic-pituitary-adrenal axis activity in patients with pathological gambling and internet use disorder. Psychiatry Res. 226 (1), 97-102.

Georgiou, P., Zanos, P., Bhat, S., Tracy, J.K., Merchenthaler, I.J., McCarthy, M.M., Gould, T.D., 2018. Dopamine and stress system modulation of sex differences in decision making. Neuropsychopharmacology 43 (2), 313.

Gianoulakis, C., Krishnan, B., Thavundayil, J., 1996. Enhanced sensitivity of pituitary ßendorphin to ethanol in subjects at high risk of alcoholism. Arch. Gen. Psychiatry 53 (3), 250-257.

Gianoulakis, C., Dai, X., Brown, T., 2003. Effect of chronic alcohol consumption on the activity of the hypothalamic-pituitary-adrenal Axis and pituitary $\beta$-endorphin as a function of alcohol intake, age, and gender. Alcohol. Clin. Exp. Res. 27 (3), 410-423.

Goeders, N.E., 2004. Stress, motivation, and drug addiction. Curr. Dir. Psychol. Sci. 13 (1), 33-35.

Goldstein, A.L., Stewart, S.H., Hoaken, P.N., Flett, G.L., 2014. Mood, motives, and gam- bling in young adults: an examination of within-and between-person variations using experience sampling. Psychol. Addict. Behav. 28 (1), 217.

Goodman, A., 1990. Addiction: definition and implications. Br. J. Addict. 85 (11), 1403-1408.

Goodman, A., 2008. Neurobiology of addiction: an integrative review. Biochem. Pharmacol. 75 (1), 266-322.

Goudriaan, A.E., Lapauw, B., Ruige, J., Feyen, E., Kaufman, J.-M., Brand, M., Vingerhoets, G., 2010. The influence of high-normal testosterone levels on risk-taking in healthy males in a 1-week letrozole administration study. Psychoneuroendocrinology 35 (9), 1416-1421. 
Grant, J.E., Brewer, J.A., Potenza, M.N., 2006. The neurobiology of substance and be- havioral addictions. CNS Spectrums 11 (12), 924-930.

Greenwald, M.K., 2018. Anti-stress neuropharmacological mechanisms and targets for addiction treatment: a translational framework. Neurobiol. Stress 9, 84-104.

Griffiths, M.D., 1990. The cognitive psychology of gambling. J. Gambl. Stud. 6 (1), 31-42.

Griffiths, M., 1995. The role of subjective mood states in the maintenance of fruit machine gambling behaviour. J. Gambl. Stud. 11 (2), 123-135.

Härkönen, M., Ylikahri, R., 1983. Acute effects of alcohol on female sex hormones. Alcohol. Clin. Exp. Res. 7 (3), 289-293.

Harvey, S.M., Beckman, L.J., 1985. Cyclic fluctuation in alcohol consumption among female social drinkers. Alcohol. Clin. Exp. Res. 9 (5), 465-471.

Hasselblatt, M., Krieg-Hartig, C., Hüfner, M., Halaris, A., Ehrenreich, H., 2003. Persistent disturbance of the hypothalamic-pituitary-gonadal axis in abstinent alcoholic men. Alcohol Alcohol. 38 (3), 239-242.

Heather, N., 1998. A conceptual framework for explaining drug addiction. J. Psychopharmacol. 12 (1), 3-7.

Heinz, A., Rommelspacher, H., Gräf, K.-J., Kürten, I., Otto, M., Baumgartner, A., 1995. Hypothalamic-pituitarygonadal axis, prolactin, and cortisol in alcoholics during withdrawal and after three weeks of abstinence: comparison with healthy control subjects. Psychiatry Res. 56 (1), 81-95.

Helms, C.M., Messaoudi, I., Jeng, S., Freeman, W.M., Vrana, K.E., Grant, K.A., 2012. A longitudinal analysis of circulating stress-related proteins and chronic ethanol self- administration in cynomolgus macaques. Alcohol. Clin. Exp. Res. 36 (6), 995-1003.

Hogarth, L., Hardy, L., Mathew, A.R., Hitsman, B., 2018. Negative mood-induced alcohol- seeking is greater in young adults who report depression symptoms, drinking to cope, and subjective reactivity. Exp. Clin. Psychopharmacol. 26 (2), 138.

Hönekopp, J., Bartholdt, L., Beier, L., Liebert, A., 2007. Second to fourth digit length ratio (2D: 4D) and adult sex hormone levels: new data and a meta-analytic review.

Psychoneuroendocrinology 32 (4), 313-321.

Horvath, C.W., 2004. Measuring television addiction. J. Broadcast. Electron. Media 48 (3), 378-398.

Hudson, A., Stamp, J.A., 2011. Ovarian hormones and propensity to drug relapse: a re- view. Neurosci. Biobehav. Rev. 35 (3), 427-436.

Jana, K., Jana, N., De, D.K., Guha, S.K., 2010. Ethanol induces mouse spermatogenic cell apoptosis in vivo through over-expression of Fas/Fas-L, p53, and caspase-3 along with cytochrome c translocation and glutathione depletion. Mol. Reprod. Dev. 77 (9), 820-833.

Joyce, K.M., Hudson, A., O'Connor, R., Thompson, K., Hodgin, M., Perrot, T., Stewart, S.H., 2018. Changes in coping and social motives for drinking and alcohol con-sumption across the menstrual cycle. Depress. Anxiety 35 (4), 313-320.

Junghanns, K., Backhaus, J., Tietz, U., Lange, W., Bernzen, J., Wetterling, T., Rink, L., Driessen, M., 2003. Impaired serum cortisol stress response is a predictor of early relapse. Alcohol Alcohol. 38 (2), $189-193$.

Junghanns, K., Tietz, U., Dibbelt, L., Kuether, M., Jurth, R., Ehrenthal, D., Blank, S., Backhaus, J., 2004. Attenuated salivary cortisol secretion under cue exposure is as-sociated with early relapse. Alcohol Alcohol. 40 (1), 80-85.

Keepers, G.A., 1990. Pathological preoccupation with video games. J. Am. Acad. Child Adolesc. Psychiatry 29 (1), 49-50.

Kiefer, F., Wiedemann, K., 2004. Neuroendocrine pathways of addictive behaviour. Addict. Biol. 9 (3-4), 205-212.

King, A.C., Errico, A.L., Parsons, O.A., 1995. Eysenck's personality dimensions and sex steroids in male abstinent alcoholics and nonalcoholics: an exploratory study. Biol. Psychol. 39 (2-3), 103-113.

King, A., Munisamy, G., de Wit, H., Lin, S., 2006. Attenuated cortisol response to alcohol in heavy social drinkers. Int. J. Psychophysiol. 59 (3), 203-209.

Kraemer, W.J., Loebel, C.C., Volek, J.S., Ratamess, N.A., Newton, R.U., Wickham, R.B., Gotshalk, L.A., Duncan, N.D., Mazzetti, S.A., Gómez, A.L., 2001. The effect of heavy resistance exercise on the circadian rhythm of salivary testosterone in men. Eur. J. Appl. Physiol. 84 (1-2), 13-18.

Krueger, T.H., Schedlowski, M., Meyer, G., 2005. Cortisol and heart rate measures during casino gambling in relation to impulsivity. Neuropsychobiology 52 (4), 206-211.

La Grange, L., Jones, T.D., Erb, L., Reyes, E., 1995. Alcohol consumption: biochemical and personality correlates 
in a college student population. Addict. Behav. 20 (1), 93-103.

LaBrie, J.W., Hummer, J.F., Pedersen, E.R., 2007. Reasons for drinking in the college student context: the differential role and risk of the social motivator. J. Stud. Alcohol Drugs 68 (3), 393-398.

Labudda, K., Wolf, O.T., Markowitsch, H.J., Brand, M., 2007. Decision-making and neuroendocrine responses in pathological gamblers. Psychiatry Res. 153 (3), 233-243.

Lawrence, A.J., Luty, J., Bogdan, N.A., Sahakian, B.J., Clark, L., 2009a. Impulsivity and response inhibition in alcohol dependence and problem gambling.

Psychopharmacology 207 (1), 163-172.

Lawrence, A.J., Luty, J., Bogdan, N.A., Sahakian, B.J., Clark, L., 2009b. Problem gamblers share deficits in impulsive decision-making with alcohol-dependent individuals.

Addiction 104 (6), 1006-1015.

Lee, C., Ludwig, S., Duerksen, D.R., 2002. Low-serum cortisol associated with opioid use: case report and review of the literature. Endocrinologist 12 (1), 5-8.

Leeman, R.F., Potenza, M.N., 2012. Similarities and differences between pathological gambling and substance use disorders: a focus on impulsivity and compulsivity. Psychopharmacology 219 (2), 469-490.

Lenz, B., Mueller, C.P., Stoessel, C., Sperling, W., Biermann, T., Hillemacher, T., Bleich, S., Kornhuber, J., 2012a. Sex hormone activity in alcohol addiction: integrating orga-nizational and activational effects. Prog. Neurobiol. 96 (1), 136-163.

Lenz, B., Müller, C.P., Kornhuber, J., 2012b. Alcohol dependence in same-sex and op- posite-sex twins. J. Neural Transm. 119 (12), 1561-1564.

Lenz, B., Mühle, C., Braun, B., Weinland, C., Bouna-Pyrrou, P., Behrens, J., Kubis, S., Mikolaiczik, K., Muschler, M.R., Saigali, S., 2017. Prenatal and adult androgen ac- tivities in alcohol dependence. Acta Psychiatr. Scand. 136 (1), 96-107.

Li, Y., Sescousse, G., Dreher, J.-C., 2014. Endogenous cortisol levels are associated with an imbalanced striatal sensitivity to monetary versus non-monetary cues in patho- logical gamblers. Front. Behav. Neurosci. 8 , 83.

Lindman, R.E., Koskelainen, B.M., Peter Eriksson, C., 1999. Drinking, menstrual cycle, and female sexuality: a diary study. Alcohol. Clin. Exp. Res. 23 (1), 169-173.

Lloyd, J., Doll, H., Hawton, K., Dutton, W.H., Geddes, J.R., Goodwin, G.M., Rogers, R.D., 2010. How psychological symptoms relate to different motivations for gambling: anonline study of internet gamblers. Biol. Psychiatry 68 (8), 733-740.

Luijten, M., Schellekens, A.F., Kühn, S., Machielse, M.W., Sescousse, G., 2017. Disruption of reward processing in addiction: an image-based meta-analysis of functional mag- netic resonance imaging studies. Jama Psychiatry $74(4), 387-398$.

Lynch, W.J., Sofuoglu, M., 2010. Role of progesterone in nicotine addiction: evidence from initiation to relapse. Exp. Clin. Psychopharmacol. 18 (6), 451.

Magrys, S., Olmstead, M., 2015. Acute stress increases voluntary consumption of alcohol in undergraduates. Alcohol Alcohol. 50 (2), 213-218.

Magrys, S., Olmstead, M., Wynne-Edwards, K., Balodis, I., 2013. Neuroendocrinological responses to alcohol intoxication in healthy males: relationship with impulsivity, drinking behavior, and subjective effects. Psychophysiology 50 (2), 204-209.

Maneesh, M., Dutta, S., Chakrabarti, A., Vasudevan, D., 2006. Alcohol abuse-duration dependent decrease in plasma testosterone and antioxidants in males. Indian J. Physiol. Pharmacol. 50 (3), 291.

Maniaci, G., Goudriaan, A., Cannizzaro, C., van Holst, R., 2018. Impulsivity and stress response in pathological gamblers during the trier social stress test. J. Gambl. Stud. 34 (1), 147-160.

Martin, A., Curry, A.G.M.T., Martin, D., Catherine, 1999. Alcohol use in adolescent fe- males: correlates with estradiol and testosterone. Am. J. Addict. 8 (1), 9-14.

Matthews, N., Farnsworth, B., Griffiths, M.D., 2009. A pilot study of problem gambling among student online gamblers: mood states as predictors of problematic behavior. CyberPsychol. Behav. 12 (6), 741-745.

Mehta, P.H., Beer, J., 2010. Neural mechanisms of the testosterone-aggression relation: the role of orbitofrontal cortex. J. Cogn. Neurosci. 22 (10), 2357-2368.

Mendelson, J.H., Stein, S., 1966. Serum cortisol levels in alcoholic and nonalcoholic subjects during experimentally induced ethanol intoxication. Psychosom. Med. 28 (4), 616-626.

Mendelson, J.H., Stein, S., McGuire, M.T., 1966. Comparative psychophysiological studies of alcoholic and 
nonalcoholic subjects undergoing experimentally induced ethanol intoxication. Psychosom. Med. 28 (1), 112.

Mendelson, J.H., Mello, N.K., Ellingboe, J., 1977. Effects of acute alcohol intake on pi- tuitary-gonadal hormones in normal human males. J. Pharmacol. Exp. Ther. 202 (3), 676-682.

Mendelson, J.H., Mello, N.K., Ellingboe, J., 1981. Acute alcohol intake and pituitary gonadal hormones in normal human females. J. Pharmacol. Exp. Ther. 218 (1), 23-26.

Meyer, G., Hauffa, B.P., Schedlowski, M., Pawlak, C., Stadler, M.A., Exton, M.S., 2000. Casino gambling increases heart rate and salivary cortisol in regular gamblers. Biol. Psychiatry 48 (9), 948-953.

Meyer, G., Schwertfeger, J., Exton, M.S., Janssen, O.E., Knapp, W., Stadler, M.A., Schedlowski, M., Krüger, T.H., 2004. Neuroendocrine response to casino gambling in problem gamblers. Psychoneuroendocrinology 29 (10), 1272-1280.

Milivojevic, V., Sinha, R., 2018. Central and peripheral biomarkers of stress response for addiction risk and relapse vulnerability. Trends Mol. Med. 24 (2), 173-186.

Mishra, S., Morgan, M., Lalumiere, M.L., Williams, R.J., 2010. Mood and audience effects on video lottery terminal gambling. J. Gambl. Stud. 26 (3), 373-386.

Møller, A., Rømer Thomsen, K., Brooks, D.J., Mouridsen, K., Blicher, J.U., Hansen, K.V., Lou, H.C., 2019. Attenuation of dopamine-induced GABA release in problem gam- blers. Brain Behav. 9 (3), e01239.

Motaghinejad, M., Bangash, M.Y., Motaghinejad, O., 2015. Attenuation of alcohol with- drawal syndrome and blood cortisol level with forced exercise in comparison with diazepam. Acta Medica Iranica 311-316.

Muehlhan, M., Höcker, A., Miller, R., Trautmann, S., Wiedemann, K., Lotzin, A., Barnow, S., Schäfer, I., 2018. HPA axis stress reactivity and hair cortisol concentrations in recently detoxified alcoholics and healthy controls with and without childhood maltreatment. Addict. Biol. 1-8.

Muthusami, K., Chinnaswamy, P., 2005. Effect of chronic alcoholism on male fertility hormones and semen quality. Fertil. Steril. 84 (4), 919-924.

Nitkowska, M., Tomasiuk, R., Czyżyk, M., Friedman, A., 2015. Prolactin and sex hor- mones levels in males with Parkinson's disease. Acta Neurol. Scand. 131 (6), 411-416.

Nofsinger, J.R., Patterson, F.M., Shank, C.A., 2018. Decision-making, financial risk aversion, and behavioral biases: the role of testosterone and stress. Econ. Hum. Biol. 29, 1-16.

Nolen-Hoeksema, S., Hilt, L., 2006. Possible contributors to the gender differences in alcohol use and problems. J. Gen. Psychol. 133 (4), 357-374.

Orio, L., Antón, M., Rodríguez-Rojo, I.C., Correas, Á., García-Bueno, B., Corral, M., de Fonseca, F.R., GarcíaMoreno, L.M., Maestú, F., Cadaveira, F., 2018. Young alcohol binge drinkers have elevated blood endotoxin, peripheral inflammation and low cortisol levels: neuropsychological correlations in women. Addict. Biol. 23 (5), 1130-1144.

Ortner, G.R., Wibral, M., Becker, A., Dohmen, T., Klingmüller, D., Falk, A., Weber, B., 2013. No evidence for an effect of testosterone administration on delay discounting in male university students. Psychoneuroendocrinology 38 (9), 1814-1818.

Paris, J.J., Franco, C., Sodano, R., Freidenberg, B., Gordis, E., Anderson, D.A., Forsyth, J.P., Wulfert, E., Frye, C.A., 2010a. Sex differences in salivary cortisol in response to acute stressors among healthy participants, in recreational or pathological gamblers, and in those with posttraumatic stress disorder. Horm. Behav. 57 (1), 35-45.

Paris, J., Franco, C., Sodano, R., Frye, C., Wulfert, E., 2010b. Gambling pathology is associated with dampened cortisol response among men and women. Physiol. Behav. 99 (2), 230-233.

Passelergue, P., Robert, A., Lac, G., 1995. Salivary cortisol and testosterone variations during an official and a simulated weight-lifting competition. Int. J. Sports Med. 16 (5), 298-303.

Peele, S., Brodsky, A., 1975. Love and Addiction.

Persky, H., O’Brien, C.P., Fine, E., Howard, W.J., Khan, M.A., Beck, R.W., 1977. The effect

of alcohol and smoking on testosterone function and aggression in chronic alcoholics. Am. J. Psychiatry 134 (6), 621-625.

Peters, S., Jolles, D.J., Van Duijvenvoorde, A.C., Crone, E.A., Peper, J.S., 2015. The link between testosterone and amygdala-orbitofrontal cortex connectivity in adolescent alcohol use. Psychoneuroendocrinology 53, 117-126.

Phillips, B., Hajela, R., Hilton Jr., D.L., 2015. Sex addiction as a disease: evidence for assessment, diagnosis, and response to critics. Sex. Addict. Compuls. 22 (2), 167-192. 
Plotsky, P.M., 1991. Pathways to the secretion of adrenocorticotropin: a view from the portal. J. Neuroendocrinol. 3 (1), 1-9.

Potenza, M.N., 2008. The neurobiology of pathological gambling and drug addiction: an overview and new findings. Philos. Trans. Royal Soc. B: Biol. Sci. 363 (1507), 3181-3189.

Purdy, R.H., Valenzuela, C.F., Janak, P.H., Finn, D.A., Biggio, G., Bäckström, T., 2005. Neuroactive steroids and ethanol. Alcohol. Clin. Exp. Res. 29 (7), 1292-1298.

Purohit, V., 2000. Can alcohol promote aromatization of androgens to estrogens? A re- view. Alcohol 22 (3), 123-127.

Rachdaoui, N., Sarkar, D.K., 2017. Pathophysiology of the effects of alcohol abuse on the endocrine system. Alcohol Res. 38 (2), 255.

Ramirez, L.F., McCormick, R.A., Lowy, M.T., 1988. Plasma cortisol and depression in pathological gamblers. Br. J. Psychiatry 153 (5), 684-686.

Ravitz, B., Nutt, J., 1991. Disturbances of Hypotha1amicPituitary-Adrena1 Axis func- tioning during ethanol withdrawal in six men. Am. J. Psychiatry 1 (48), 1023.

Ready, R., Friedman, J., Grace, J., Fernandez, H., 2004. Testosterone deficiency and apathy in Parkinson's disease: a pilot study. J. Neurol. Neurosurg. Psychiatry 75 (9), 1323-1326.

Richardson, G.S., 1990. Circadian rhythms and aging. In: Handbook of the Biology of Aging, pp. 275-305.

Rogers, P., 1998. The cognitive psychology of lottery gambling: a theoretical review. J. Gambl. Stud. 14 (2), 111-134.

Rosanna, M., Carolina, F., Marco, F., Luca, P., Carmelo, A., Claudia, L., Rosa, D., 2016. Sex differences in alcohol use disorders: the role of steroid hormones.

Ruttle, P.L., Maslowsky, J., Armstrong, J.M., Burk, L.R., Essex, M.J., 2015. Longitudinal associations between diurnal cortisol slope and alcohol use across adolescence: a seven-year prospective study. Psychoneuroendocrinology 56, 23-28.

Sanna, E., Talani, G., Busonero, F., Pisu, M.G., Purdy, R.H., Serra, M., Biggio, G., 2004. Brain steroidogenesis mediates ethanol modulation of GABAA receptor activity in rat hippocampus. J. Neurosci. 24 (29), 65216530.

Sanna, P., Kawamura, T., Chen, J., Koob, G., Roberts, A., Vendruscolo, L., Repunte- Canonigo, V., 2016. 11ßhydroxysteroid dehydrogenase inhibition as a new potential therapeutic target for alcohol abuse. Transl. Psychiatry 6 (3), e760.

Sapienza, P., Zingales, L., Maestripieri, D., 2009. Gender differences in financial risk aversion and career choices are affected by testosterone. Proc. Natl. Acad. Sci. 106 (36), 15268-15273.

Sapolsky, R.M., 2003. Stress and plasticity in the limbic system. Neurochem. Res. 28 (11), 1735-1742.

Sarkar, D.K., 1983. Does LHRH meet the criteria for a hypothalamic releasing factor? Psychoneuroendocrinology 8 (3), 259-275.

Sarkola, T., Eriksson, C.P., 2003. Testosterone increases in men after a low dose of al- cohol. Alcohol. Clin. Exp. Res. 27 (4), 682-685.

Sarkola, T., Mäkisalo, H., Fukunaga, T., Eriksson, C.P., 1999. Acute effect of alcohol on estradiol, estrone, progesterone, prolactin, cortisol, and luteinizing hormone in pre- menopausal women. Alcohol. Clin. Exp. Res. 23 (6), 976-982.

Schliep, K.C., Zarek, S.M., Schisterman, E.F., Wactawski-Wende, J., Trevisan, M., Sjaarda, L.A., Perkins, N.J., Mumford, S.L., 2015. Alcohol intake, reproductive hormones, and menstrual cycle function: a prospective cohort study. Am. J. Clin. Nutr. 102 (4), 933-942.

Selye, H., 1936. A syndrome produced by diverse nocuous agents. Nature 138 (3479), 32. Serre, F., Fatseas, M.,

Swendsen, J., Auriacombe, M., 2015. Ecological momentary assessment in the investigation of craving and substance use in daily life: a systematic review. Drug Alcohol Depend. 148, 1-20.

Shabtai, Y., Bendelac, L., Jubran, H., Hirschberg, J., Fainsod, A., 2018. Acetaldehyde inhibits retinoic acid biosynthesis to mediate alcohol teratogenicity. Sci. Rep. 8 (1), 347.

Sierksma, A., Sarkola, T., Eriksson, C.P., van der Gaag, M.S., Grobbee, D.E., Hendriks, H.F., 2004. Effect of moderate alcohol consumption on plasma dehydroepian- drosterone sulfate, testosterone, and estradiol levels in middle-aged men and post- menopausal women: a diet-controlled intervention study. Alcohol. Clin. Exp. Res. 28 (5), 780-785.

Sinha, R., 2001. How does stress increase risk of drug abuse and relapse? Psychopharmacology 158 (4), 343-359.

Sinha, R., O'Malley, S.S., 1999. Craving for alcohol: findings from the clinic and the la- boratory. Alcohol and 
Alcoholism (Oxford, Oxfordshire) 34 (2), 223-230.

Stålenheim, E.G., Eriksson, E., von Knorring, L., Wide, L., 1998. Testosterone as a bio- logical marker in psychopathy and alcoholism. Psychiatry Res. 77 (2), 79-88.

Stanton, S.J., Liening, S.H., Schultheiss, O.C., 2011. Testosterone is positively associated with risk taking in the lowa gambling task. Horm. Behav. 59 (2), 252-256.

Starcke, K., van Holst, R.J., van den Brink, W., Veltman, D.J., Goudriaan, A.E., 2013. Physiological and E ndocrine $R$ eactions to $P$ sychosocial $S$ tress in a lcohol $U$ se $D$ isorders: $D$ uration of a bstinence $M$ atters. Alcohol. Clin. Exp. Res. 37 (8), 1343-1350.

Steiner, E.T., Barchard, K.A., Meana, M., Hadi, F., Gray, P.B., 2010. The deal on testos-terone responses to poker competition. Curr. Psychol. 29 (1), 45-51.

Stenstrom, E., Saad, G., 2011. Testosterone, financial risk-taking, and pathological gambling. J. Neurosci. Psychol. Econ. 4 (4), 254.

Stephens, M.A.C., Wand, G., 2012. Stress and the HPA axi: role of glucocorticoids in alcohol dependence. Alcohol Res. 34 (4), 468-483.

Steptoe, A., Ussher, M., 2006. Smoking, cortisol and nicotine. Int. J. Psychophysiol. 59 (3), 228-235.

Stevenson, B.L., Dvorak, R.D., Kramer, M.P., Peterson, R.S., Dunn, M.E., Leary, A.V., Pinto, D., 2019. Within-and between-person associations from mood to alcohol consequences: the mediating role of enhancement and coping drinking motives. J. Abnorm. Psychol. 128 (8), 813.

Sussman, S., Sussman, A.N., 2011. Considering the definition of addiction. In: Molecular Diversity Preservation International.

Sutker, P.B., Libet, J.M., Allain, A.N., Randall, C.L., 1983. Alcohol use, negative mood states, and menstrual cycle phases. Alcohol. Clin. Exp. Res. 7 (3), 327-331.

Swendsen, J.D., Tennen, H., Carney, M.A., Affleck, G., Willard, A., Hromi, A., 2000. Mood and alcohol consumption: an experience sampling test of the self-medication hy- pothesis. J. Abnorm. Psychol. 109 (2), 198.

Taherianfard, M., Shariaty, M., 2004. Evaluation of Serum Steroid Hormones in Schizophrenic Patients.

Takahashi, T., 2004. Cortisol levels and time-discounting of monetary gain in humans. Neuroreport 15 (13), 2145-2147.

Takahashi, T., Sakaguchi, K., Oki, M., Homma, S., Hasegawa, T., 2006. Testosterone le- vels and discounting delayed monetary gains and losses in male humans. Neuro Endocrinol Lett. 27 (4), 439-444.

Tenover, J.S., Matsumoto, A.M., Clifton, D.K., Bremner, W.J., 1988. Age-related altera- tions in the circadian rhythms of pulsatile luteinizing hormone and testosterone se- cretion in healthy men. J. Gerontol. 43 (6), M163-M169.

Terner, J.M., De Wit, H., 2006. Menstrual cycle phase and responses to drugs of abuse in humans. Drug Alcohol Depend. 84 (1), 1-13.

Thayer, J.F., Hall, M., Sollers III, J.J., Fischer, J.E., 2006. Alcohol use, urinary cortisol, and heart rate variability in apparently healthy men: evidence for impaired inhibitory control of the HPA axis in heavy drinkers. Int. J. Psychophysiol. 59 (3), 244-250.

Tong, M.-H., Yang, Q.-E., Davis, J.C., Griswold, M.D., 2013. Retinol dehydrogenase 10 is indispensible for spermatogenesis in juvenile males. Proc. Natl. Acad. Sci. 110 (2), 543-548.

Toren, P., Dor, J., Rehavi, M., Weizman, A., 1996. Hypothalamic-pituitary-ovarian axis and mood. Biol. Psychiatry 40 (10), 1051-1055.

Touitou, Y., 1995. Effects of ageing on endocrine and neuroendocrine rhythms in humans. Horm. Res. Paediatr. 43 (1-3), 12-19.

Touitou, Y., Haus, E., 2000. Alterations with aging of the endocrine and neuroendocrine circadian system in humans. Chronobiol. Int. 17 (3), 369-390.

Uhart, M., Wand, G.S., 2009. Stress, alcohol and drug interaction: an update of human research. Addict. Biol. 14 (1), 43-64.

Välimäki, M.J., Härkönen, M., Eriksson, C.P., Ylikahri, R.H., 1984a. Sex hormones and adrenocortical steroids in men acutely intoxicated with ethanol. Alcohol 1 (1), 89-93.

Välimäki, M., Pelkonen, R., Härkönen, M., Ylikahri, R., 1984b. Hormonal changes in noncirrhotic male alcoholics during ethanol withdrawal. Alcohol Alcohol. 19 (3), 235-242.

Välimäki, M., Pelkonen, R., Härkönen, M., Tuomala, P., Koistinen, P., Roine, R., Ylikahri, R., 1990. Pituitarygonadal hormones and adrenal androgens in non-cirrhotic female alcoholics after cessation of alcohol intake. 
Eur. J. Clin. Investig. 20 (2Part1), 177-181.

van Anders, S.M., Goldey, K.L., Conley, T.D., Snipes, D.J., Patel, D.A., 2012. Safer sex as the bolder choice: testosterone is positively correlated with safer sex behaviorally relevant attitudes in young men. J. Sex. Med. 9 (3), 727-734.

Van den Bos, R., Harteveld, M., Stoop, H., 2009. Stress and decision-making in humans: performance is related to cortisol reactivity, albeit differently in men and women. Psychoneuroendocrinology 34 (10), 1449-1458.

van Honk, J., Schutter, D.J., Hermans, E.J., Putman, P., 2003. Low cortisol levels and the balance between punishment sensitivity and reward dependency. Neuroreport 14(15), 1993-1996.

van Honk, J., Schutter, D.J., Hermans, E.J., Putman, P., Tuiten, A., Koppeschaar, H., 2004. Testosterone shifts the balance between sensitivity for punishment and reward in healthy young women.

Psychoneuroendocrinology 29 (7), 937-943.

Van Honk, J., Will, G.-J., Terburg, D., Raub, W., Eisenegger, C., Buskens, V., 2016. Effects of testosterone administration on strategic gambling in poker play. Sci. Rep. 6, 18096.

Van Wingen, G.A., Ossewaarde, L., Bäckström, T., Hermans, E.J., Fernández, G., 2011. Gonadal hormone regulation of the emotion circuitry in humans. Neuroscience 191, 38-45.

Verdejo-García, A., Lawrence, A.J., Clark, L., 2008. Impulsivity as a vulnerability marker for substance-use disorders: review of findings from high-risk research, problem gamblers and genetic association studies. Neurosci. Biobehav. Rev. 32 (4), 777-810.

Verdejo-Garcia, A., Clark, L., Verdejo-Roman, J., Albein-Urios, N., Martinez-Gonzalez, J.M., Gutierrez, B., Soriano-Mas, C., 2015. Neural substrates of cognitive flexibility in cocaine and gambling addictions. Br. J. Psychiatry 207 (2), 158-164.

Wallin-Miller, K., Li, G., Kelishani, D., Wood, R.I., 2018. Anabolic-androgenic steroids alter decision making in a balanced rodent model of the lowa gambling task. Behav. Neurosci. 132 (3), 152.

Walter, M., Gerhard, U., Gerlach, M., Weijers, H.-G., Boening, J., Wiesbeck, G.A., 2006a. Controlled study on the combined effect of alcohol and tobacco smoking on testos- terone in alcohol-dependent men. Alcohol Alcohol. 42 (1), 19-23.

Walter, M., Gerhard, U., Gerlach, M., Weijers, H.G., Boening, J., Wiesbeck, G.A., 2006b. CLINICAL STUDY: cortisol concentrations, stress-coping styles after withdrawal and long-term abstinence in alcohol dependence. Addict. Biol. 11 (2), 157-162.

Wand, G.S., Dobs, A.S., 1991. Alterations in the hypothalamic-pituitary-adrenal axis in actively drinking alcoholics. J. Clin. Endocrinol. Metab. 72 (6), 1290-1295.

Wareham, J.D., Potenza, M.N., 2010. Pathological gambling and substance use disorders. Am. J. Drug Alcohol Abuse 36 (5), 242-247.

Wemm, S.E., Sinha, R., 2019. Drug-induced stress responses and addiction risk and re- lapse. Neurobiol. Stress 10, 100148.

Wemm, S., Fanean, A., Baker, A., Blough, E.R., Mewaldt, S., Bardi, M., 2013. Problematic drinking and physiological responses among female college students. Alcohol 47 (2), 149-157.

Wemm, S.E., Cao, Z., Han, L., Wulfert, E., 2018. Stress responding and stress-related changes in cue reactivity in heavy smokers, problem gamblers, and healthy controls. Addict. Biol. 1-10.

West, R., Brown, J., 2013. Theory of Addiction. John Wiley \& Sons.

White, R.E., Thornhill, S., Hampson, E., 2006. Entrepreneurs and evolutionary biology: the relationship between testosterone and new venture creation. Organ. Behav. Hum. Decis. Process. 100 (1), 21-34.

Worhunsky, P.D., Potenza, M.N., Rogers, R.D., 2017. Alterations in functional brain networks associated with loss-chasing in gambling disorder and cocaine-use disorder. Drug Alcohol Depend. 178, 363-371.

Wu, A.H., Whittemore, A.S., Kolonel, L.N., John, E.M., Gallagher, R.P., West, D.W., Hankin, J., Teh, C.Z., Dreon, D.M., Paffenbarger, R., 1995. Serum androgens and sex hormone-binding globulins in relation to lifestyle factors in older African-American, white, and Asian men in the United States and Canada. Cancer Epidemiol. Prevent. Biomarkers 4 (7), 735-741.

Wu, Y., Liao, J., Zilioli, S., Wu, Y., Deng, H., Li, H., Tobler, P.N., 2019. Testosterone administration increases social discounting in healthy males.

Psychoneuroendocrinology 108, 127-134.

Wu, Y., Shen, B., Liao, J., Li, Y., Zilioli, S., Li, H., 2020. Single dose testosterone ad- ministration increases impulsivity in the intertemporal choice task among healthy males. Horm. Behav. 118, 104634. 

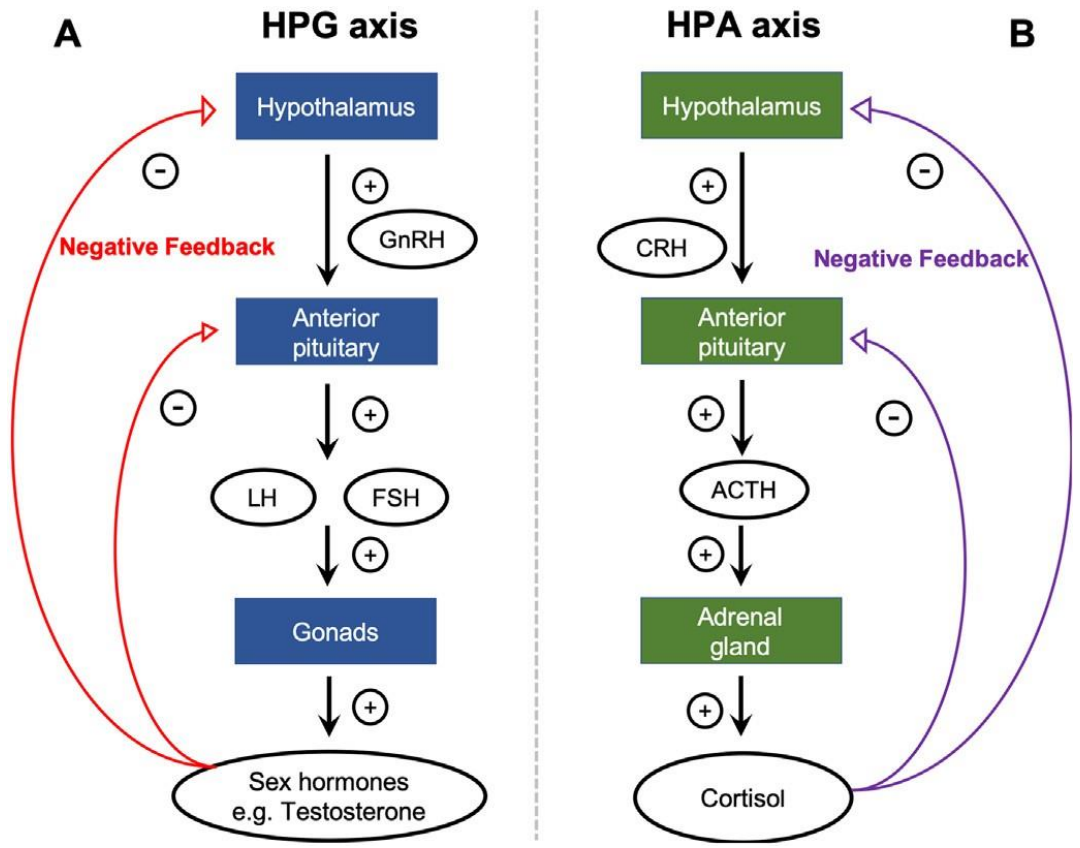

Fig. 1. Hormone production. (A) The key elements of the hypothalamic-pituitary-gonadal axis; (B) The key components of the hypothalamic-pituitaryadrenal axis. $\mathrm{GnRH}$, gonadotropin-releasing hormone; $\mathrm{LH}$, luteinizing hormone; $\mathrm{FSH}$, follicle-stimulating hormone. $\mathrm{CRH}$, corticotropin-releasing hormone; $\mathrm{ACTH}$, adrenocorticotropic hormone.
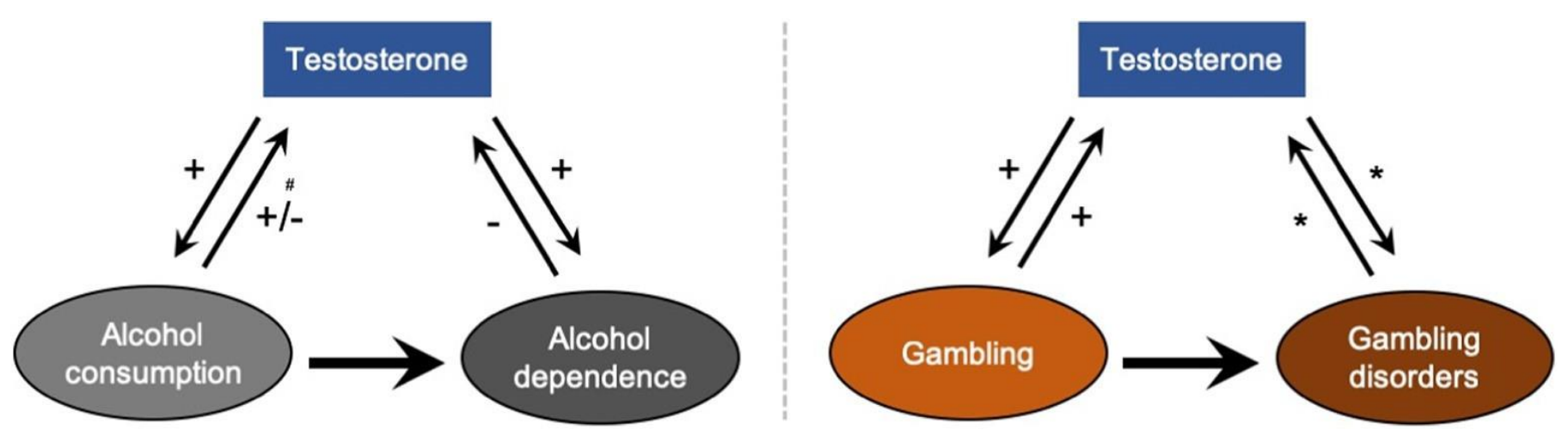

Fig. 2. Bidirectional relationship between testosterone and substance and nonsubstance abuse in humans. (Left) Dynamic interplay between testosterone levels and alcohol consumption in individuals with and without alcohol dependence. + indicates an inductive link; - denotes an inhibitory link; \# implies dose-dependent relationship. Note that there are sex-specific effects of testosterone and thus this association is more strong in males. (Right) 

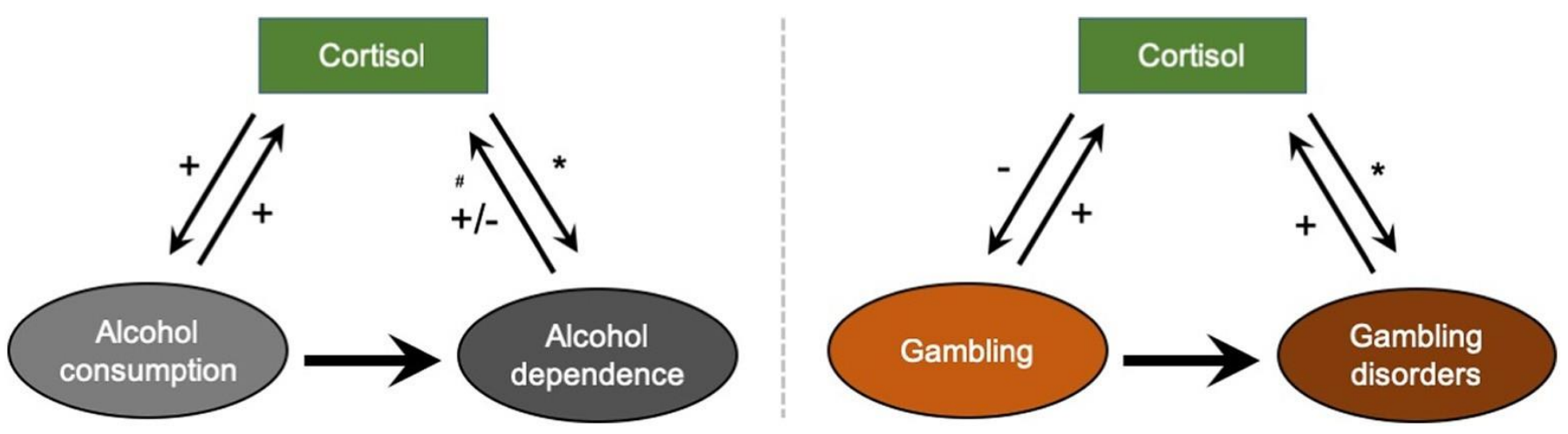

Fig. 3. The bidirectional relationship between cortisol and substance and nonsubstance abuse in humans. (Left) The dynamic interplay between cortisol levels and alcohol consumption in individuals with and without alcohol dependence. + indicates an inductive link; - denotes an inhibitory link; \# implies a blunted phasic response but elevated tonic levels in 